\title{
Individualistic Philanthropy: The Paradox of Embodied Participation for
}

\section{Health-Related Fundraising Campaigns}

\section{Julie Robert, School of International Studies, UTS}

The full version of this paper is also available from:

International Journal of Nonprofit and Voluntary Sector Marketing

Int. J. Nonprofit Volunt. Sect. Mark. (2013)

Published online in Wiley Online Library

(wileyonlinelibrary.com) DOI: 10.1002/nvsm.1471

\section{Abstract}

Movember and Julyna have emerged as examples of health-related fundraising and awareness campaigns that require embodied participation in the form of temporary body modification. Reaching a younger demographic not traditionally motivated by appeals to altruism, these campaigns have capitalized on the signifying power of the body to reflect and construct identities and self-perceptions to motivate participation. Taking a cultural studies approach and employing visual, textual and discursive analyses of the campaigns' websites, a primary vector for information dissemination and recruitment, this study highlights how philanthropic activity has been successfully coded as making participants more physically, sexually, and socially desirable. In promoting such individualistic motives for philanthropy, however, these campaigns further a mentality that philanthropy is foremost about personal gain. The challenge these initiatives pose is how to convert participants from individualistic to altruistic models of philanthropy.

Keywords: Movember, Julyna, Embodiment, Philanthropy, Individualism

\section{Introduction}

Philanthropy and 'concepts such as altruism, beneficence, concern for strangers, donation, gift, responsiveness to unmet need and voluntariness' (Meslin, Rooney, \& Wolf, 2008, p. 46S) go hand to hand. What could be less individualistic, at least so goes the rhetoric, than helping to raise money for preventative and treatment-oriented research or support for those coping with illnesses such as cervical cancer or depression? In both traditional and health-related philanthropy, such notions dominate 
discourses about participant motivations (Bekkers, 2006; Lee, Piliavin, \& Call, 1999; Martin, 1994; Verhaert \& Poel, 2010; Wilhelm \& Bekkers, 2010). When participants occupy the middle ground between fully medicalized forms of involvement (donating blood, living-organ or tissue donation) and those that simply ask for gifts of time and/or money, however, shifts toward a more individualistic discourse of involvement and personal benefit seem to occur. These slippages are not of the egoistic kind in which donors contribute to appease their own discomfort when personally solicited to donate (Bekkers, 2006; Verhaert \& Poel, 2010), but are rather motivated by the kind of contribution they are entreated to make.

Using visual, textual and discursive analyses of the Movember Australia and Julyna (Canada) websites, this broad-based cultural studies paper draws on philanthropy studies and sociological theories of the body to interrogate the tension between individualistic and altruistic appeals to participants for health-related fundraising campaigns that require embodied but non-medicalized forms of participation. Movember and Julyna call upon participants to engage in specific practices of body modification - moustache growing for the former and pubic hair grooming for the latter-for a one-month period while raising funds and awareness for health-related charities. Both campaigns employ rhetoric that focuses on the ways in which participants can either consolidate their identity as, or undertake philanthropic projects to become more physically, sexually, and socially attractive individuals. In combination with the individualized meaning-making that comes from techniques of body modification (Gill, Henwood, \& McLean, 2005; Patterson \& Schroeder, 2010; Sweetman, 2012; Talley, 2012) and the body projects of late modernity (Featherstone, 2007; Shilling, 2012) these campaigns present themselves as highly individualized undertakings in which the fashioning of the participant's identity as a fun, attractive, successful, hyper-masculine/feminine, style-conscious individual is in productive tension with the meaning-making centered on altruism that comes from philanthropic activities.

Although philanthropy has almost always been motivated by a confluence of factors, some of which are individualistic or self-serving, the kind of embodied philanthropy required by campaigns like Movember and Julyna perpetuate a relatively new model based on hyper-individualization. A better understanding of campaigns of this nature, 
which is to say that center their personal motivational draws on body projects and the individual meaning-making that comes from them, provides insight into different enticements that appeal to a young demographic that has typically been more reluctant to engage in traditional forms of philanthropy (Meslin et al., 2008). The study of these new initiatives and the unpacking of (part of) their appeal consequently hold significant promise for those looking to (better) engage young adults in prosocial behavior. Such explorations also help to explain the concomitant trend of criticism of participants who engage in campaign-specific body modification as part social phenomena represented by these initiatives, but not as philanthropic activity (c.f. Nickel \& Eikenberry, 2009; Wirgau, Farley, \& Jensen, 2010). The challenge of these campaigns, however, will be converting those whose initial experience of philanthropy is self-fulfillment and individual gain to more traditional forms of giving that rely on more altruistic (or at least less obviously self-serving) motivations.

\section{Background to the Case Studies}

Movember, began in 2003 as a Australian initiative that has men grow moustaches, collect pledges for the maintenance of their facial hair and raise awareness of men's health issues, namely prostate cancer and mental health concerns such as depression. Despite its origins as a barroom phenomenon, an excuse for young, primarily heterosexual Anglo-Australian men to ironically embrace a grooming practice more associated with heterosexual icons of the 1970s, gay counterculture and porn stars (Peterkin, 2001), Movember has become a global phenomenon. It now garners celebrity endorsements ranging from trusted figures such as national newscasters to paragons of the sports world such as the Wallabies, the Australian national rugby team, and the Montreal Canadiens professional ice hockey team. It boasts of ranking in the top 100 of global NGOs for impact, innovation, accountability and efficiency (Movember, 2013).

By contrast, Julyna is a still fledgling Canadian project, initiated in 2011, that calls on women to grow out a palette of pubic hair and to wax and maintain it in a stylized design in the name of cervical cancer awareness and research into its prevention and treatment. Participants collect pledges for their grooming endeavors and frequent 
partner salons, which donate proceeds for the month of July, to have their pubic coifs restyled.

Julyna's early marketing and its facial hair-inspired waxing templates (the moustache, the David Suzuki - in reference to the Canadian ecologist's distinctive facial hair) clearly identify it as being inspired by Movember's success. The similarities between programs are therefore both obvious and understandable. Both campaigns welcome participants of all ages, but the cultural references and visual styling employed seem to be oriented toward adults in their twenties and thirties. Furthermore, savvy marketing and social media strategies have emerged as central to both efforts, which suggests a desire to reach those plugged in to social networking sites such as Twitter and Facebook. These marketing and media efforts are used to recruit participants, to inform members of the wider public about the campaign's health-related aims and to allow participants to connect with each other, either through forums for exchange, to share stories of their involvement or to recognize top-earning fundraisers. This last function has an off-line analogue in the form of much-publicized gala events that mark the end of the campaign and which allow participants to showcase their hirsute forms of participation. Although some of these strategies (galas, competitive fundraisers) have been mainstays of modern philanthropy, others have been introduced more recently and help to distinguish campaigns like these as a new form of philanthropy that is reaching a generation that came of age with social media.

\section{Methodology}

This study is anchored in the humanities-based methodologies of cultural studies. Specifically, visual, textual and discursive analyses were employed. The sources scrutinized were those of the 2012 editions of the Movember (Australia) and Julyna (Canada) websites. All pages directly linking to the homepages were included. Close readings of text probed for connotative meanings (popular associations, etc.) and emphasis (use of punctuation, strong language, syntax). Visual analyses focused on considerations of what aspects of an image were relatively dominant or discordant in contrast to other elements in the same visual field and other images employed on the campaign's site. 


\section{Embodied Philanthropy}

This analysis is premised on a link between traditional forms of (health related) philanthropy and the embodied philanthropy demanded by these new and relatively unstudied initiatives. Marketized philanthropy, with its focus on non-altruistic motivators, also serves as a valuable point of reference. The closest analogue to the campaigns in question might be fundraising events such as 'fun runs' or various 'thon' type activities (charity marathons, bike-a-thons, swim-a-thons). King contends that the rise of thons is linked, on the one hand to imperatives of self-betterment through personal fitness and neo-liberal discourses of public health that privileged notions of responsibility for one's own well-being, and on the other to 'post-yuppie, anti-materialism' of the 1990s, which spurred a need to 'do something' more than give money (2006: 49). Olivola (2011) argues that deeper psychological motives toward martyrdom might both influence participation and favorably affect the levels of sponsorship, especially when the cause in question, such as combatting disease, is linked to human suffering. Although grooming is unlikely to constitute martyrdom, the public health climate of self-maintenance and betterment King describes still exerts considerable sway.

The campaigns' objectives centering on health and the bodily nature of the philanthropic activity also make health-related philanthropy useful for understanding the factors motivating the temporary and non-medical uses of the body for charitable ends. Bekkers (2006) claims that resources—one's ability to give without too much sacrifice - are a determining factor of prosocial behavior, particularly in healthrelated philanthropy where the resources of health and time dominate motivational concerns. Blood donation, for example, is impossible if one is anemic, has certain diseases or even carries an elevated epidemiological risk for certain infections such as HIV. Meslin, Rooney and Wolf (2008) uphold time, evidenced by the propensity to volunteer in other contexts, as a primary resource determinant of biological donation due to the demands that the physical act of donating or recovery might pose.

With Movember and Julyna, health and time — but not money — are similarly likely to be the primary resource-implications among those considered in existing studies. Unlike in the medicalized context of health-related philanthropy, however, the 
barriers to participation are very low. Participants must be physically able to grow (and groom) body hair. This requirement precludes those with certain medical conditions such as alopecia, Klinefelter's syndrome or ironically given the cancercentered health awareness aims of both initiatives, those who may have temporarily lost their hair due to chemotherapy treatments. The highly gendered nature of the campaigns has also served to exclude members of the opposite sex, although there is little biological reason for this exclusion given that pubic hair is a feature of both male and female bodies and that many women (including those of some ethnic backgrounds and those who are post-menopausal) have varying amounts of facial hair. ${ }^{1}$ The demands on time are minimal and in many cases the embodied philanthropic processes require no extra time of the participant. Although there may be incidental costs (salon service or moustache wax), participants themselves are neither required nor entreated to make direct financial contributions to the campaigns. There are neither entry fees, nor registration costs, a criticism of many 'event'-style fundraisers (Olivola, 2011). Indeed the primary fundraising vehicle is third-party sponsorship. Thus in contrast to many forms of marketized philanthropy, which require the purchase of goods as the defining act of participation, embodied philanthropy erects few financial barriers.

Despite the emphasis on resource considerations, these should be thought of more as the preconditions for philanthropy rather than as the deciding motivation to participate. Empathy, care for others and various other altruistic motivations are widely recognized as prominent motivators for both traditional and health-related philanthropy, but they are far from the only incentives. Martin reasons that 'mixed motives' are altogether typical in philanthropy of all sorts: 'Philanthropy offers numerous avenues for self-fulfilling service, at least when a match is found between personal interests and philanthropic opportunities' (1994, p. xi). Eikenberry's (2009) research into giving circles, new community-based philanthropic initiatives, cites camaraderie, education about the philanthropic process, career-oriented networking, the ability to see tangible results of one's gifts and the opportunity to focus on issues one cares most about as examples of non-altruistic motives for engaging in philanthropy. Whether the motivation is a form of martyrdom, a sense of selfsatisfaction or even more direct personal gains like a tax break, understanding these personal incentives is a central part of successful fundraising design (Martin, 1994). 
Both Martin and Eikenberry argue that these more individualistic motivations should not mire philanthropy in cynicism, because doing so would impose an unreasonable and discrediting ideal that the only philanthropy that is valid is that which is done for purely altruistic reasons. Nickel and Eikenberry (2009) nonetheless argue that the 'better than nothing' line of defense is a slippery slope that contributes to the reasons for need for philanthropy (injustice, inequality, environmental degradation, unhealthy diets of processed foods) being obscured by the notion that 'effective measures' like cause-related marketing and high-profile fundraisers are in place to deal with the effects (rather than the causes) of these issues.

\section{Appealing to traditional motivators of philanthropy}

Both Movember and Julyna use clear discursive markers to identify them as charitable initiatives that have much in common with philanthropic organizations that either bypass the explicitly corporeal nature of contribution (straightforward appeals for money) or that downplay the body's role in their appeals (volunteering time).

As one surfs to the Movember Australia website, a virtual poster urges the reader to 'Donate', reassures that 'A good deed brightens a hairy world' and advertises the organization's participants as 'Deluxe change agents'. ${ }^{2}$ This welcome to the site, particularly the exhortation to donate in a font that dominates the image, clearly identifies Movember as a charity in the most common sense. It capitalizes on the notion of altruistic action by referring to the donation as a good deed and stipulates the effect of this donation, more abstract and punny than tangible, by declaring that this act will ameliorate a world that is difficult or problematic. By donating one will also facilitate change (presumably for the better), although the agency for that change - the donor, the participant, the organization as a whole - remains vague. The juxtaposition of these three phrases constructs a ready philanthropic narrative for the reader. From the act flows the positive effect and then a superlative, functional identity for the person who responds to the call.

On the 'About Movember' page, the question of agency becomes clearer, but the overtones of philanthropy remain constant. Readers are introduced to the campaign's participants as: 'these selfless and generous men known as Mo Bros'. The adjectives 
here, like in the virtual poster, resonate with the vernacular associated with traditional charities. Unlike these more common efforts, however, it is the campaign participant - the grower of the moustache — who is celebrated as the altruist and the sponsor who is, largely by omission, relegated to a supporting, and largely financial, role. In this, the Mo Bro is cast as the 'hero' of the fundraising campaign and is able to avoid the negative stereotypes of the fundraiser as the person who implores others for money. Although this will be part of the role, it is downplayed in favor of more positive associations.

The Mo Bro is praised as not only the primary altruist, but as an educator in the larger public health arena: 'Mo Bros effectively become walking, talking billboards for the 30 days of November and through their actions and words raise awareness by prompting private and public conversation around the often ignored issue of men's health'. The 'About Movember' links to the organizations sponsored by the initiative (Prostate Cancer Foundation of Australia and BeyondBlue, a mental health initiative) and although these affiliations are listed on the main page, one cannot link directly to them from the homepage to find out more about their programs, policies or health information. The 'About Movember' page also features a 3-minute long YouTube video that boast of the campaign's impact on awareness about men's health issues. This is measured not in statistics about early detection (a favorite measure of promammography campaigns), but rather in estimates of the number (1.9 billion) of 'conversations about Movember \& men's health'. The participant is therefore construed as a skilled volunteer who lends his body to the cause, but who also donates time, in the form of conversations, to the pedagogical efforts to increase awareness and action on men's health initiatives. The participant becomes an activist, an ambassador for a cause. He thus transcends the simple role of volunteer, fundraiser or donor and becomes a key player in not only the philanthropic endeavor, but also in the campaign's public health aims. The rhetoric is laudatory, increasing the score of the philanthropic role that the participant plays, although what concrete outcomes a Mo Bro is responsible for remain almost impossible to calculate.

For Julyna, the philanthropic and altruistic rhetoric is considerably subtler. The 'What is Julyna?' page, for instance, identifies the organization as a charitable one and the familiar daffodil graphic proclaims it a 'proud supporter' of the Canadian Cancer 
Society. ${ }^{3}$ The goals, 'to fundraise and spread awareness about this harmful disease [cervical cancer]' are also listed. The founder's message seems to concentrate on health education and awareness, which may not be surprising given the founder, Vanessa Willson, is a registered nurse. In contrast to Movember, the Julyna homepage features links to information about cervical cancer provided by an oncologist at McGill University, which suggests that the campaign itself (if not the participants) takes the health education aspect seriously.

By comparison, the campaign's fundraising and sponsorship components take a backseat, for the inducements to donate/participate are relatively subtle: 'So to all you philanthropists out there-get creative and get generous! Please donate to the cause by participating or sponsoring someone who is styling this Julyna'. The organizing team behind Julyna, as yet a not-for-profit initiative with no professional staff, is also recognized as " 14 committed Canadians who volunteer their time and expertise because they believe in Julyna's mission'. This rhetoric of volunteerism and commitment to a cause is perhaps the strongest tie to traditional philanthropic discourse, although it does not extend beyond the organizers. This leaves the status of Julyna's participants more uncertain. They, along with those who would lend financial support to their efforts, are interpellated as philanthropists by the call to get involved, but their embodied philanthropic contribution is conceived of in ambiguous terms; it is not recognized as volunteerism in the same way that Movember acknowledges the hair-related efforts of its participants.

It is perhaps because the conventional discourses of philanthropy are not as evident with Julyna that the appearance-conscious body projects required to participate have generated considerable debate about participants' motives and have prompted accusations that participants are simply engaging in vain pursuits in the name of charity. Echoing critiques of other forms of philanthropy which emphasize the benefit to the giver (Wirgau et al., 2010), the press and the public responded both with serious questions about Julyna's design, but also with criticisms of participants' motivations. 'This just smells like lazy faux activism to me,' wrote one blog commenter in response to a post about the campaign (Hodge, 2011). A series of newspaper articles (Dempsey, 2011; Smith, 2011) have derided the effectiveness of grooming a private area of the body in name of raising the public profile of a 
stigmatized disease, effectively suggesting that participants are either naïve or in it for other reasons. With Movember, the 'moustache first, charity second' refrain is typified by Jacobson, who cites the origins of Movember as an ironic fashion revival among friends drinking beer that was justified only by turning the fad into a charitable endeavor: 'Prostate cancer is relegated to being of secondary importance. In comparison, the desire to raise money for breast cancer pre-empted the CIBC Run for the Cure' (2010, p. 67). The assessments of the mixed motives for philanthropy that operate in relation to Movember and Julyna tend to focus on what participants stand to gain from their involvement and how the focus on the body project may detract from the larger (health) issues represented.

If, as Eikenberry (2009) and Martin (1994) contend, non-corporeal forms of philanthropy intersect with processes of positive identity formation and selfperception, for instance that one is a generous person, health related philanthropy elicits comparable mixed motivations. Bennett and Savani (1994) have found that the willingness to donate a body part is highly influenced by the alignment of this act, a 'symbolic statement', with the donor's self-perception (or aspirational selfperception) as an altruistic person. Those involved in sustained or repeated forms of health-related philanthropy, such as repeat blood donation, form identities based upon an incorporation of the specific role, blood donor, into their identities (Callero, Howard, \& Piliavin, 1987; Lee et al., 1999; Piliavin \& Callero, 1991). One thus becomes a biological philanthropist as opposed to engaging in acts of biological philanthropy. Similar (although perhaps more cynical) desires to be seen as 'good corporate citizens' have been cited by companies keen to reap the rewards of sponsorships and cause-related marketing ventures (Adkins, 2012; King, 2006; Polonsky \& Wood, 2001). This shift from thinking about philanthropic acts to identity or image predicated on these acts takes on particular importance when the body, its uses and practices are at stake (Foucault, 1978). The body itself is therefore a locus for meanings about identity, philanthropic and otherwise.

\section{The Embodied Individual}

The embodied forms of contribution prescribed by Movember and Julyna are practices that in our present late-capitalist context - along with other procedures such 
as tattooing, piercing, cosmetic surgery, diets and exercise regimes-are tightly associated with expressions of identity. Chris Shilling argues that the body has become a locus for the articulation of one's identity: 'In the affluent West there is a tendency for the body to be seen as an entity which is in the process of becoming: a project which should be worked at and accomplished as part of an individual's selfidentity' (2012 original emphasis). He concludes that body projects are part of an externalization of our desires to be recognized as a particular type of individual. Paul Sweetman expands upon this notion, contending that body modifications are 'manifestations of an increasingly tight relationship between the body and identity, and attempts to construct a self of self-identity though attention to the body - and, more particularly, its appearance - in a context where identities cannot otherwise be readily assumed' (2012, p. 248). Sweetman here suggests that body modification as a meaning-making project for the self and cites Patterson and Schroeder's (2010) suggestion that impermanent modifications of the genre demanded by the campaigns in question are about changeability and one's capacity to move in and out of different social groups and formulations of one's identity.

Insofar as the body communicates with the outside world, it conveys information about identity. Like many other signs and phenomena, bodies often pass by unnoticed, even by those who are responsible for their (unconscious) articulation. Still, there is often a deliberate effort to use the body to craft both an image and a self-image. As what Sweetman calls a 'plastic resource' (2012, p. 249), the body becomes an object that can be manipulated and worked both upon and with to express, often simultaneously, a current identity and an aspirational self-conception (Featherstone, 2007). The body becomes the surface upon which desires, attempts at identity formulation and assays of belonging are projected and enacted.

Although there is tremendous scope for diversity and therefore individualized identity-projects within the range of possible body projects, many of them are highly conventional. Losing weight, coloring grey hairs and working out to achieve a trimmer or more muscular physique are particularly common and are often not even recognized as attempts at individualizing body modification. This is especially so in a context where more extreme practices, framed as expressions of individuality, dominate both popular and academic literature. In the case of connotation-rich body 
projects that are broadly recognized as such, the body work is generally acknowledged (at least among those who share a cultural context) as attempts to construct identity in accordance with (or occasionally in defiance of) these connotations. The middle-aged turn to Botox, the teenager's choice to dye their hair bold colors, the hairstyles or facial hair required by certain religious sects or the plastic surgery that diminishes the ethno-racial distinctiveness of certain facial features are commonly recognized as attempts to be, or to at least appear to be, young, rebellious, devout or a member of the homogenously, non-radicalized majority.

It is this wide acceptance of what certain body projects signify that allows embodied philanthropic initiatives to play with bodily meanings and to interpellate participants not as people necessarily desiring of a certain type of body or feature, but as ones desirous of being (or being perceived as) as certain kind of person. The Movember moustache on a normally clean-shaven or bearded man, thanks to the campaign's wide recognition, now expresses an at least partial desire to be seen as an altruistic individual. I nonetheless contend that the body projects at the heart of these campaigns target not so much the potential participant's desire to be seen as altruistic or philanthropic, but to be perceived as a member of a socially and culturally privileged demographic targeted by the campaign. Altruism may therefore be a consequence of participation, but-judging by the appeals to a non-philanthropic identity that body campaigns present — it may not necessarily be the motivating factor.

\section{Appealing To Individualistic Motivators of Philanthropy}

If both campaigns use explicit references to conventional philanthropy and suggest how contributions, both from sponsoring donors and participants, will contribute to feelings of having done 'something for a good cause', they also both broadcast a rhetoric and a visual style that is meant to appeal and motivate on a more personal level. The online presences of both campaigns target a certain sort of person, an ideal participant, and also suggest the ways in which participation can transform a participant into an idealized version of themselves. There is therefore an interpellative reinforcement of identity already associated with certain bodily practices and appearances and a promise of holistic metamorphosis through the modification of the body. 
For Movember, great emphasis is placed on the moustache's power to transform boys into respectable, esteemed men in the heteronormative traditions of virility and fatherhood, as well as in relation to iconic figures of masculinity from previous eras, such as prominent politicians, ranking military officials, and more recently, macho celebrities such as Tom Selleck and sexually successful male porn stars. That male facial hair, a marker of the onset of puberty and thus the signal of transition from boyhood to manhood, is linked to such identity-centered connotations is by no means a stretch of the imagination. After all, Peterkin (2001) contends that the appearance of male facial hair and the inculcation to the practices of its grooming are linked not only to the onset of manhood, but also to a stereotypical moment of apprenticeship in which fathers teach their sons to shave.

The 2012 Movember website and the posters made freely available to participants to display, for instance in their places of business, accordingly emphasize the father-son relationship. Drawing on this learned grooming ritual, they insinuate that the act of not shaving (or only partially shaving) function as a rite of passage in the initiation to or cultivation of adult masculinity. In one image, an older and a middle-aged man stand side by side. Both sport moustaches and they bear a resemblance to each other. On the posters, the wording announces the 2012 event as 'Movember and Sons,' confirming the (purported) paternal relationship between the two. The 'and sons' designation, often used as a naming practice for family businesses, imparts a sense of continuity and familial apprenticeship as well as inheritance. The son, through the cultivation of his moustache, can follow in his father's footsteps to become the successful, virile man his father is.

This family business orientation carries through into other images and slogans as well. An image of an Asian mustachioed man - the only Asian face featured on the website - in another of the main page's welcome banners is accompanied by the line 'purveyors of knowledge and fine moustaches'. The Movember participant thus becomes a successful service provider of knowledge and a retailer of fine goods, clear indicators of capitalistic success. These commercial attributes are moreover linked to masculinity in its fullest forms, for the primary slogan attached to the image proclaims 'You're gonna be a Man my Son'. Manhood—capitalized to add 
emphasis - is upheld as the unqualified ideal to which one aspires and orients one's actions. The 'son' of the paternalistic phrase meanwhile denotes both the filial relationship evoked elsewhere and the patronizing nickname that one would use in conversation with somebody considered one's junior or uninitiated counterpart. The transformation from boyhood and the status of amateur to mature initiate operates through the body project of the moustache.

Most of the images on the site feature men in what would appear to be in their twenties or thirties. The middle-aged or older men are severely outnumbered. The implication for younger men looking at the site is that they are in good company as a Mo Bro. For older men, the youthful orientation of site's visuals gestures toward an inclusive, youthful, community predicated on the sporting of a moustache. If one is defined by the company one keeps, the older participant becomes youthful. Alternatively, he becomes the mentor, the father figure of the exceptional images.

Movember participants are also interpellated as knight-like in the description of the month-end festivities in which the participants and their supporters 'celebrate their gallantry and valor'. The implication is that the mustachioed men, by virtue of their participation, become the crusading figures from both history and myth who dispatch foes, display their loyalty through physical prowess, defend the innocent and protect female virtue. The critiques of knightly behavior notwithstanding (Gravdal, 1991), knights have popularly been upheld as models of European, and by extension Western, masculinity. The codes of behavior and thought associated with knighthood are largely incommensurate with the modern age, but both men and women esteem the knight (in shining armor!) as a fantasy for either male emulation or female desire.

The sexual allure of the Mo Bro is a cornerstone of the campaign's rhetoric. Indeed, the Mo Sista, defined as 'a woman who loves a Mo', has been created as a sort of para-participant with her own official role in the campaign. This role consists of supporting the men's moustache growing efforts, primarily through the conferral of their (romantic) attentions. The Sista, is entreated to bestow encouragement and affection on the Mo Bro: 
For many Mo Bros, the thought of growing a moustache can be a daunting one. They may be concerned about how they will look with their newly acquired facial friend, nervous as to whether they are capable of growing a Mo or apprehensive about the commitment it takes to grow a Mo for the full 30 days of Movember. Mo Sistas play a vital role in supporting the journey, not least by being supportive of their courageous commitment. A kind word of encouragement, a wink or a smile of recognition can go a long way to helping a Mo Bro as he navigates the month of Movember - this may be particularly true in the first few weeks when growth can, for some, be a little bit slow.

The Sista's words and gestures of support enable the timid would-be participant to conceive of himself as courageous and committed. The Sista is meant to use her engagement with the participant - the kind words, the winks, the smiles and other signs of flirtation - to reinforce the notion that Mo Bro is a paragon of heteronormative masculinity who attracts a woman's attention and endorsement.

This is shown to somewhat comic effect in a public service announcement promoting the campaign. In this commercial, an attractive woman (slim, buxom, blond) is shown walking down the street past numerous young, attractive and clean-shaven men. Although they clearly admire her and signal their interest, she passes them by without giving them a second glance. When a slightly portly, middle-aged man with a moustache walks by her, however, she turns around to admire him, reversing the earlier attempts at making a passing connection. The woman's unlikely engagement with this participant reinforces the notion that the man with a moustache, despite the scene being reminiscent of the practice of 'cruising' among gay men, is the object of heterosexual female desire.

The moustache accordingly becomes not just the symbol of men's health initiatives, but the territory it occupies on the upper lip metonymically makes the whole male body a site of engagement in a project that frames participants as men who conform to (or who through their participation will conform to) stereotypical notions of masculinity, financial success, good (even noble) lineage, sex appeal and chivalrous comportment. All of this, of course, is in addition to the altruistic and health- 
conscious qualities conferred by the very fact that the participant is engaging in a health-related charitable event. Indeed, through a series of slippages from sign to site, from body work to identity project, the moustache makes the man.

Julyna's play with body projects as constitutive of identity is focused not so much on the outwardly transformative power of the grooming practice initiated by the campaign, but rather on a consolidation and evidencing of desirable traits through participation and a redefinition of a private act into a public statement. The campaign lends a seriousness of purpose to the outwardly 'frivolous' practice of pubic hair grooming such that it can no longer be questioned as an act that is peripheral or even contrary to the more substantive questions like those of women's health and sexuality. The campaign's rhetoric accordingly centers on building socially and culturally legitimized justifications into an already popular but controversial practice.

The first step in this process, the consolidation and evidencing of desirable traits, is performed quite effectively by Julyna's visual messaging. Public service announcements aired on Canadian television and subsequently rebroadcast on YouTube, for instance, feature a series of scenes one would expect to encounter in a beauty salon. Slender women with well-toned, white, limbs are pictured, from the neck down, in and surrounded by the paraphernalia of the beauty salon: smocks, height-adjustable chairs, hair dryers and handheld mirrors. These objects and the camera's focus are nonetheless displaced from the head to the pudenda. The slogan entreats the viewer, following the example of the women featured, to try a new look, the implication being that the hair that will be styled, however is that 'down there'.

Despite the provocative and potentially scandalous invitation, the message does not challenge the viewer, for if she identifies with the appearance-conscious women featured, defined by one who takes care of the hair on her head, Julyna is only the logical extension of a regime of style-guided self-care. Julyna is thus akin to any other exhortation of the beauty-industry wherein failure to comply risks the participant being out of style or off trend. Avoiding such a fate, however, comes at minimal cost. Not only would many of the would be participants already be exercising some form of pubic hair grooming (especially in the summer), but transforming their normal wax 
into a philanthropic one comes with all the identity benefits of being recognized a contributor to charity.

The interpellation of the stylish (or aspirationally stylish) woman echoes in the photos of the 2012 gala posted to the website as a digital slideshow. The collection features young, striking women in dresses that would not be out of place at a trendy nightclub, posed suggestively, either in small groups, with equally attractive and well-dressed men or in candid, action shots featuring people in conversation or dancing. In the posed shots, they are smiling or displaying a sultry look, often with a drink in hand, implying an overall atmosphere of revelry, youthful and stylish sophistication and sex appeal. The photo that depicts the evening's entertainment, Las Vegas style showgirls attired in flamboyant feathered and sequined costumes, defines the evening as having a carnivalesque atmosphere. Julyna is therefore framed less as a charitable or healthfocused endeavor than it is as a destination or event that welcomes those who are (or who see themselves as wanting to be) on the exclusive guest list.

Julyna does not emphasize its philanthropic nature as much as Movember and its visual messaging mostly seems to play up the appearance-driven facets of its campaign. The actual rhetoric used on the website is nevertheless that of combativeness: 'Because when our womanhood is threatened, it's up to all of us to take a stand, put our hair up and get down to business.' The possessive article (our) and the reinforced pronoun (all of us) emphasize collective action and imply a sense of community. The threat to womanhood solicits a response (taking a stand) that has overtones of militancy and industriousness, traits traditionally associated with masculinity. These traits, however, are recast in feminine terms (putting our hair up) as examples of women's agency over their own health. This sentence exemplifies the trend, identified by Machin and Thornborrow (2003) in their analysis of Cosmopolitan magazine, of promoting women's independence through a set of practices that paradoxically link female agency to sexuality and the body. Julyna's core demographic is young, stylish, urban professional women, those who are likely to have come of age reading about how to become the 'fun, fearless, female' vaunted by Cosmopolitan. These women are thus interpellated to their roles as participants by the campaign's rhetoric. They are motivated not by altruistic motives, but by being able to prove, using a highly intimate form of individual action, that there is nothing a 
'stylish vajayjay can't accomplish'. Style and a sexualized body are made purposeful, cancer beating and unifying for the women involved even if they cannot be made altruistic.

Julyna's relative abandonment of philanthropic discourses might hinge on the potential critiques of vanity and frivolousness connected with feminine beauty rituals in general and the kinds of practices associated with young women in particular. As perhaps the most maligned of these practices-dismissed by Terry Eagleton as a trivial practice unworthy of cultural attention (Tondeur, 2006)—pubic hair grooming is an ideal candidate for semiotic rehabilitation. As a part of a larger preoccupation with physical appearance, an issue treated by Naomi Wolf in The Beauty Myth (1990) as being a distraction from the larger concerns of feminism, pubic hair waxing has the potential to have triggered feelings (both individual and collective) of shame, guilt and denial, especially for those women who see themselves as feminists or concerned with women's issues, such as women's health. To transform the allegedly frivolous act of pubic hair grooming into a productive one, ostensibly in line with feminist issues and popular discourses of female empowerment, however, allows for a mitigation of those potential negative feelings.

Like the moustache sported in November, during July a participant's normal bikini wax is no longer a selfish aesthetic practice or one that is oriented toward pleasing a partner (Dault, 2011). It becomes at once a charitable contribution (by having it done at a sponsoring salon that donates profits to the charity), a talking point to destigmatize the human papilloma virus, a reminder to have an annual pap smear and a marker of a woman's constitution as a 'fighter' in the battle against the larger war against cancer in its myriad forms. Instead of representing the sexualization or the pornification of women and their pudenda, the muff-for-a-cause both destigmatizes mainstream female sexuality and, ostensibly, raises awareness of the preventability of a disease that frequently stems from a sexually transmitted infection. It becomes an instrument of women's sexual rights. Instead of being a silly expenditure of money aimed at one's own vanity or catering to ideals of sexual beauty dictated by men or pornography, a dedicated Julyna wax allows participant to achieve the same physical result they value as style-conscious, sexually attractive women whilst rationalizing the practice that might otherwise be seen controversial or undermining of women. The 
campaign therefore emphasizes traits that are likely to be valued by individuals in their self-formulations - empowered, fun-loving, appearance-conscious, successfulbut gives them socially-valued altruistic and health-conscious overtones. In this, what for many women of the target audience has become a routine practice-depilation of pubic hair during summer bathing suit weather-becomes an act that, at least ostensibly, combats its negative connotation and valorizes rather than trivializes the person who engages in it.

\section{Conclusion}

If the discourses of philanthropy in the participatory public health campaigns are weak, ambiguous or conventional, but the campaigns themselves have been popular (to varying degrees), it suggest that initiatives of this kind are tapping into motivators for philanthropy for target audiences. ${ }^{4}$ Olivola found that 'people care a lot about the means of achieving altruistic goals' (Olivola, 2011, pp. 59, original emphasis). The modification and play with and on the body and its surfaces accordingly arises as a driving force in this emerging kind philanthropy. Both Movember and Julyna present themselves as initiatives for public good in the form of disease prevention, health promotion, charitable giving and other forms of prosocial behavior, but they also represent themselves as a means for achieving personal goals and crafting individual self-image through temporary body projects.

Clearly positioning themselves to appeal to a demographic of twenty and thirtysomethings with time and the inclination to invest in their appearance, these campaigns have embraced the theories of mixed motivations for philanthropy. Seemingly subscribing to a rationale of the charitable ends justifying the individualistic means, Movember has become incredibly popular and has given rise to dozens of imitators, of which Julyna is one. What remains to be seen is how this emerging approach to philanthropy on the part of both participants and campaign designers will evolve. Will the Mo Bros of today switch to traditional philanthropy with less explicit or fantastical appeals to what contributors stand to gain in the future? Or will a demographic of Julyna participants enticed to contribute when it means something to them change the way that philanthropy is conducted? 
If nothing else, these campaigns have shown ways in which a new demographic can be incited to engage with the idea of philanthropy at practically no cost to themselves. This might constitute a first step in fostering altruistic sensibilities that might subsequently be converted or 'stepped up' to more traditional forms of philanthropy. Having experienced the benefits of philanthropy, even as by-products of the pursuit of other aims, participants may be more willing to volunteer, give time or donate in other health-related ways in the future. Campaigns such as Movember and Julyna, while still requiring further empirical studies centering on participant motivations and responses, ought not be dismissed due to the 'superficial' ways in which some participants engage with the initiatives and their aims. Rather, organizations have much to gain from understanding both how to interpellate this erstwhile resistant demographic to philanthropic activity and to convert their participation to more sustained, less individualistic and more substantive forms once involved.

\footnotetext{
1 The critiques of gender exclusion have opened up both the campaigns studied here and others to a more inclusive orientation. Movember, for instance, created the role of Mo Sista for women wishing to get involved, although this ancillary role is still not viewed as an equal opportunity for participation (Jacobson). Julyna's most recently updated website (2013) features a naked man (his genitals concealed between his legs) with unkempt body hair except for a perfectly waxed, heart-shaped patch of pubic hair. A new Australian initiative, Fanuary, calls on both women and men to engage in pubic hair styling despite a name that plays upon a British slang term for female genitalia (Fanuary 2013).

2 All references to the Movember website and its subsidiary pages, unless otherwise identified, refer to the Australian site used leading up to and during the November 2012 campaign. (Movember, 2012)

${ }^{3}$ All references to the Julyna website and its subsidiary pages, unless otherwise identified, refer to the site used to promote the July 2012 campaign. (Julyna, 2012)

${ }^{4}$ The Movember Australia page boasts 90000 Facebook 'likes' for the global movement and cites over $\$ 120$ million (AUD) raised globally in 2011 alone. A more modest campaign, Julyna nonetheless vaunts its $\$ 55000$ earnings in its first year as a largely local initiative centred in Toronto.
} 


\section{References}

Adkins, Sue. 2012. Cause related marketing. Routledge: New York.

Bekkers, René. 2006. Traditional and Health-Related Philanthropy: The Role of Resources and Personality. Social Psychology Quarterly, 69(4): 349-366.

Bennett, Roger, \& Savani, Sharmila. 1994. Factors Influencing the Willingness to Donate Body Parts for Transplanations. Journal of Health \& Social Policy, 18(3): 61-85.

Callero, Peter L., Howard, Judith A., \& Piliavin, Jane A. 1987. Helping Behavior as Role Behavior: Disclosing Social Structure and History in the Analysis of Prosocial Action. Social Psychology Quarterly, 50(3): 247-256.

Dault, Meredith Suzanne. 2011. The Last Triangle: Sex, Money and the Politics of Pubic Hair. (MA), Queen's University, Kingston, ON.

Dempsey, Ann. 2011. Julyna Raises Eyebrows... and \$50, 000: Down-There Hair Grooming Donations To Go To Cervical Cancer Research, Toronto Star, 19/08/2011.

Eikenberry, Angela M. 2009. Giving Circles: Philanthropy, Voluntary Association, and Democracy. Indiana University Press: Bloomington.

Featherstone, Mike. 2007. Consumer Culture and Postmodernism (2nd ed.). Sage: London.

Foucault, M. 1978. The history of sexuality: An introduction. Vol. 1. New York: Vintage.

Gill, Rosalind, Henwood, Karen, \& McLean, Carl. 2005. Body Projects and the Regulation of Normative Masculinity. Body and Society, 11(1): 37-62.

Gravdal, K. 1991. Ravishing Maidens: Writing Rape in Medieval French Literature and Law. University of Pennsylvania Press: Philadelphia.

Hodge, Jarrah. 2011. The Julyna Controversy. http://www.genderfocus.com/2011/07/04/the-julyna-controversy/.

Jacobson, Jenna Leigh. 2010. Moustachioed Men and Marathon Moms: The Marketing of Cancer Philanthropy. (MA), Wilfrid Laurier University, Waterloo, ON.

Julyna. 2012. Julyna. http://www.julyna.com/ [16/11/2012].

Julyna. 2013. Julyna. http://www.julyna.com/ [28/01/2013].

King, Samantha. 2006. Pink Ribbons, Inc.: Breast Cancer adn the Politics of Philanthropy. University of Minnesota Press: Minneapolis.

Lee, Lichang, Piliavin, Jane Allyn, \& Call, Vaughn R. A. 1999. Giving Time, Money, and Blood: Similarities and Differences. Social Psychology Quarterly, 62(3): 276-290.

Machin, David, \& Thornborrow, Joanna. 2003. Branding and Discourse: The Case of Cosmopolitan. Discourse \& Society, 14(4): 453-471.

Martin, Mike W. 1994. Virtuous Giving: Philanthropy, Voluntary Service, and Caring. Indiana University Press: Bloomington.

Meslin, Eric M., Rooney, Patrick M., \& Wolf, James G. 2008. Health-Related Philanthropy: Toward Understanding the Relationship Between the Donation of the Body (and Its Parts) and Traditional Forms of Philanthropic Giving. Nonprofit and Voluntary Sector Quarterly, 37(1): 44S-62S.

Movember. 2012. Movember. http://au.movember.com/?home [12/11/2012].

Movember. 2013. Movember. http://au.movember.com/?home [30/01/2013].

Nickel, Patricia Mooney, \& Eikenberry, Angela M. 2009. A Critique of the Discourse of Marketized Philanthropy. American Behavioral Scientist, 52(7): 974-989. 
Olivola, Christopher Y. 2011. When Noble Means Hinder Noble Ends: The Benefits and Costs of a Preference for Martyrdom in Altruism. In The Science of Giving: Experimental Approaches to the Study of Charity, D. M. Oppenheimer \& C. Y. Olivola (Eds.). Psychology Press: New York; 49-62.

Patterson, Maurice, \& Schroeder, Jonathan. 2010. Borderlines: Skin, Tattoos and Consumer Culture Theory. Marketing Theory, 10(3): 253-267.

Peterkin, Allan. 2001. One Thousand Beards: A Cultural History of Facial Hair. Arsenal Pulp Press: Vancouver.

Piliavin, Jane A., \& Callero, Peter L. 1991. Giving Blood: The Development of an Altruistic Identity. Johns Hopkins University Press: Baltimore.

Polonsky, Michael Jay, \& Wood, Greg. 2001. Can The Overcommercialization Of Cause-Related Marketing Harm Society. Journal of Macromarketing, 21(8): 8-22.

Shilling, Chris. 2012. The Body and Social Theory (Online ed.). Sage: London.

Smith, Teresa. 2011. "Julyna" Cancer Campaign Raises Hackles, The Gazette, 30/06/2011.

Sweetman, Paul. 2012. Modified Bodies: Texts, Projects and Process. In Routledge Handbook of Body Studies, B. S. Turner (Ed.). Routledge: London; 347-361.

Talley, Heather Laine. 2012. Getting Work Done: Cosmetic Surgery as Constraint, as Commodity, as Commonplace. In Routledge Handbook of Body Studies, B. S. Turner (Ed.). Sage: London; 335-346.

Tondeur, Louise. 2006. A History of Pubic Hair, or Reviewers' Responses to Terry Eagleton's After Theory. In The Last Taboo: Women and Body Hair, K. Lesnik-Oberstein (Ed.). Manchester University Press: Manchester; 48-65.

Verhaert, Griet A., \& Poel, Dirk Van den. 2010. Empathy as Added Value in Predicting Donation Behaviour Working Paper (pp. 1-28). Gent: Universiteit Gent.

Wilhelm, Mark Ottoni, \& Bekkers, René. 2010. Helping Behavior, Dispositional Empathic Concern, and the Principle of Care. Social Psychology Quarterly, 73(1): 11-32.

Wirgau, Jessica S., Farley, Kathryn Webb, \& Jensen, Courtney. 2010. Is Business Discourse Colonizing Philanthropy? A Critical Discourse Analysis of (PRODUCT) RED. Voluntas, 21: 611-630.

Wolf, Naomi. 1990. The Beauty Myth. Chatto \& Windus: London. 